\title{
Intraventricular recombinant tissue plasminogen activator for lysis of intraventricular haemorrhage
}

\author{
Veit Rohde, Carlo Schaller, Werner E Hassler
}

\begin{abstract}
A prospective series of 20 patients with moderate to severe intraventricular haemorrhage (IVH) was studied for the effect of intraventricular administration of recombinant tissue plasminogen activator (rt-PA) on reduction of haematoma volume and prognosis. On the day of haemorrhage ventriculostomy was performed and 2 to $5 \mathrm{mg}$ of $\mathrm{rt}-\mathrm{PA}$ were injected via the external ventricular drainage, followed by drainage closure for two hours. In 14 patients rt-PA treatment was repeated. Computed tomography showed complete clot lysis or substantial reduction of intraventricular haematoma volume in 19 patients within 96 hours; the clearance of the third and fourth ventricle preceded the clearance of the lateral ventricles. Decrease of ventricular enlargement was seen in all but one patient with initial ventricular dilatation. Increase of haematoma volume and ventricular size was found in one patient. Outcome was minor or no neurological deficit in nine patients, disabling neurological deficit in six patients, and vegetative status in four patients. One patient did not survive the IVH. Intraventricular treatment with rt-PA seems effective in rapid lysis of intraventricular haematoma and normalisation of impaired CSF circulation. This treatment may contribute to an improvement in prognosis of moderate to severe IVH.
\end{abstract}

(F Neurol Neurosurg Psychiatry 1995;58:447-451)

Keywords: intraventricular haemorrhage; tissue plasminogen activator; ventriculostomy; intracerebral haemorrhage

Accompanying intraventricular haemorrhage (IVH) aggravates the prognosis of intracerebral and aneurysmal haemorrhage. ${ }^{1-4}$ Haemorrhage extending into all ventricular chambers results in mortalities ranging between $60 \%$ and $91 \% .^{5-7}$ Even for partial haematocephaly mortality rates of $32 \cdot 2 \%$ to $44 \%$ were reported. ${ }^{68}$ Neurosurgical treatment including continuous ventricular drainage and transcortical evacuation of the haematoma was not effective in improving the poor prognosis of IVH. ${ }^{9}$ Serial CT studies showed spontaneous resolution of IVH within three weeks. ${ }^{10}$ Recent clinical trials have shown that urokinase and recombinant tissue plasminogen activator (rt-PA) given intraventricularly achieve reduction of intraventricular haematoma within a few days. ${ }^{11-13}$ The present study was undertaken to evaluate how the outcome could be influenced by accelerated intraventricular haematoma resolution and to assess the efficacy and safety of intraventricular fibrinolytic treatment with rt-PA.

\section{Materials and methods}

PATIENT POPULATION

Twenty patients with moderate to severe IVH diagnosed by CT were studied. There were 10 women and 10 men (age range 25 to 78 (mean 54)). In eight patients, IVH was due to rupture of an angiographically verified aneurysm of the anterior communicating or internal carotid artery. In nine patients, IVH was the result of penetration of intracerebral haematoma into the ventricles. The spontaneous brain haemorrhage was associated with hypertension in five patients and with arteriovenous malformation in four patients. In two cases the aetiology of the bleeding remained unknown despite angiography and MRI (table 1).

In 14 patients the IVH extended into all ventricles, in five patients the haematoma filled the third and fourth ventricle and a single lateral ventricle. In one patient the blood was distributed in both lateral ventricles and in the third ventricle. The grading system proposed by Graeb et al was used to assess the severity of the IVH (table 2). ${ }^{6}$ According to the grading system, nine patients presented with moderate IVH (score 5-8) and 11 patients with severe IVH (score 9-12) (table 1). The ventriculocranial ratio (ratio of the width of the ventricles between the caudate nuclei to the width of the brain at the same level) was calculated for evaluation of the ventricular size. The ratio of 0.155 was considered to be the upper limit of the normal. ${ }^{14}$ All but two patients presented with ventricular dilatation (mean 0.23).

All patients were admitted with impaired consciousness and nine were comatose. The Glasgow coma scale (GCS) score ranged from 3 to 14 (mean $8 \cdot 5$ ). ${ }^{15}$ The patient outcome was evaluated 30 to 60 days after IVH according to the Glasgow outcome scale (GOS). ${ }^{16}$

TREATMENT PROTOCOL

Informed consent for this study was obtained from or for each of the 20 patients. In all patients continuous ventricular drainage 
Table 1 Demographic and clinical characteristics and summary of results of 20 patients with moderate to severe intraventricular haemorrhage undergoing fibrinolytic intraventricular treatment with recombinant tissue plasminogen activator ( $r t-P A)$

\begin{tabular}{|c|c|c|c|c|c|c|c|c|c|c|}
\hline $\begin{array}{l}\text { Case } \\
\text { No }\end{array}$ & $\begin{array}{l}\text { Age (y), } \\
\text { Sex }\end{array}$ & Cause of IVH & $\begin{array}{l}\text { Treatment } \\
\text { days }\end{array}$ & $\begin{array}{l}\text { total } r-P A \\
\text { dosage }\end{array}$ & $\begin{array}{l}\text { Graeb score } \\
\text { pretreatment }\end{array}$ & $\begin{array}{l}\text { Graeb scoret } \\
\text { post-treatment }\end{array}$ & $\begin{array}{l}\text { VCR } \ddagger \text { pre- } \\
\text { treatment }\end{array}$ & $\begin{array}{l}\text { VCR post- } \\
\text { treatment }\end{array}$ & $\begin{array}{l}\text { Initial } \\
\text { GCS }\end{array}$ & GOS \\
\hline $\begin{array}{l}1 \\
2 \\
3 \\
4 \\
5\end{array}$ & $\begin{array}{l}52, M \\
70, \mathrm{~F} \\
55, \mathrm{~F} \\
64, \mathrm{M} \\
57, \mathrm{M}\end{array}$ & $\begin{array}{l}\text { ICH } \\
\text { ICH } \\
\text { ICH } \\
\text { ICH } \\
\text { ICH }\end{array}$ & $\begin{array}{l}1 \\
2 \\
2 \\
1 \\
3\end{array}$ & $\begin{array}{l}5 \\
5 \\
9 \\
5 \\
9\end{array}$ & $\begin{array}{r}7 \\
11 \\
6 \\
12 \\
7\end{array}$ & $\begin{array}{r}2 \\
3 \\
1 \\
12 \\
2\end{array}$ & $\begin{array}{l}0 \cdot 18 \\
0 \cdot 19 \\
0 \cdot 20 \\
0 \cdot 28 \\
0 \cdot 15\end{array}$ & $\begin{array}{l}0 \cdot 14 \\
0 \cdot 18 \\
0 \cdot 15 \\
0 \cdot 38 \\
0 \cdot 12\end{array}$ & $\begin{array}{r}13 \\
4 \\
13 \\
6 \\
11\end{array}$ & $\begin{array}{l}3 \\
3 \\
2 \\
5 \\
2\end{array}$ \\
\hline $\begin{array}{r}6 \\
7 \\
8 \\
9 \\
9 \\
10 \\
11 \\
12 \\
13\end{array}$ & $\begin{array}{l}47, M \\
78, F \\
53, M \\
40, F \\
48, F \\
63, F \\
63, F \\
41, M\end{array}$ & $\begin{array}{l}\text { AComA aneurysm } \\
\text { ICA aneurysm } \\
\text { AComA aneurysm } \\
\text { AComA aneurysm } \\
\text { ICA aneurysm } \\
\text { AComA aneurysm } \\
\text { AComA aneurysm* } \\
\text { AComA aneurysm }\end{array}$ & $\begin{array}{l}4 \\
2 \\
3 \\
2 \\
1 \\
3 \\
1 \\
2\end{array}$ & $\begin{array}{l}20 \\
10 \\
5 \\
7 \cdot 5 \\
5 \\
9 \\
5 \\
10\end{array}$ & $\begin{array}{r}12 \\
7 \\
9 \\
12 \\
10 \\
11 \\
6 \\
8\end{array}$ & $\begin{array}{l}3 \\
2 \\
4 \\
3 \\
3 \\
3 \\
0 \\
3\end{array}$ & $\begin{array}{l}0 \cdot 31 \\
0 \cdot 28 \\
0 \cdot 20 \\
0 \cdot 25 \\
0 \cdot 22 \\
0 \cdot 25 \\
0 \cdot 18 \\
0 \cdot 28\end{array}$ & $\begin{array}{l}0 \cdot 20 \\
0 \cdot 22 \\
0 \cdot 12 \\
0 \cdot 13 \\
0 \cdot 04 \\
0 \cdot 18 \\
0 \cdot 15 \\
0 \cdot 20\end{array}$ & $\begin{array}{r}5 \\
3 \\
3 \\
4 \\
4 \\
9 \\
14 \\
3\end{array}$ & $\begin{array}{l}3 \\
4 \\
4 \\
3 \\
2 \\
3 \\
1 \\
4\end{array}$ \\
\hline $\begin{array}{l}14 \\
15 \\
16 \\
17\end{array}$ & $\begin{array}{l}25, \mathrm{~F} \\
58, \mathrm{M} \\
30, \mathrm{~F} \\
65, \mathrm{M}\end{array}$ & $\begin{array}{l}\text { Temporoparietal AVM } \\
\text { Temporoparietal AVM } \\
\text { Thalamic AVM } \\
\text { Frontoparietal AVM }\end{array}$ & $\begin{array}{l}2 \\
1 \\
3 \\
3\end{array}$ & $\begin{array}{l}7 \cdot 5 \\
2 \\
7 \cdot 5 \\
6\end{array}$ & $\begin{array}{r}12 \\
9 \\
10 \\
11\end{array}$ & $\begin{array}{l}0 \\
1 \\
0 \\
6\end{array}$ & $\begin{array}{l}0 \cdot 24 \\
0.02 \\
0 \cdot 34 \\
0 \cdot 25\end{array}$ & $\begin{array}{l}0 \cdot 13 \\
0 \cdot 02 \\
0 \cdot 21 \\
0 \cdot 14\end{array}$ & $\begin{array}{r}9 \\
14 \\
5 \\
13\end{array}$ & $\begin{array}{l}1 \\
1 \\
4 \\
3\end{array}$ \\
\hline $\begin{array}{l}18 \\
19 \\
20\end{array}$ & $\begin{array}{l}43, M \\
56, M \\
67, F\end{array}$ & $\begin{array}{l}\text { Trauma } \\
\text { Unknown } \\
\text { Unknown }\end{array}$ & $\begin{array}{l}3 \\
1 \\
2\end{array}$ & $\begin{array}{r}15 \\
5 \\
10\end{array}$ & $\begin{array}{l}5 \\
6 \\
8\end{array}$ & $\begin{array}{l}3 \\
0 \\
2\end{array}$ & $\begin{array}{l}0 \cdot 24 \\
0 \cdot 24 \\
0 \cdot 24\end{array}$ & $\begin{array}{l}0 \cdot 23 \\
0 \cdot 19 \\
0 \cdot 19\end{array}$ & $\begin{array}{l}13 \\
13 \\
11\end{array}$ & $\begin{array}{l}2 \\
1 \\
2\end{array}$ \\
\hline
\end{tabular}

*Definitive haemostasis obtained before fibrinolytic intraventricular treatment with rt-PA

TTable 2 shows the grading system of Graeb et al for assessment of the severity of $\mathrm{IVH}^{6}$; VCR = ventriculocranial ratio: for grading system and normative data see text; GCS = Glasgow coma score ${ }^{15} ;$ GOS = Glasgow outcome score ${ }^{16}$

was placed through a frontal twist drill hole immediately after diagnosis of the IVH. The correct intraventricular positioning of the ventriculostomy needle was confirmed in all but one case by CT before rt-PA infusion. Two to $5 \mathrm{mg}$ of rt-PA were slowly injected via the ventriculostomy needle, followed by two hours of drainage closure. After reopening the ventricular drainage, the CSF was drained without a pressure gradient. Computed tomography was performed 16 to 24 hours after injection of rt-PA. The fibrinolytic treatment was continued until appreciable reduction of the haematoma volume in the lateral ventricles and clearance of the third and fourth ventricles were confirmed; in seven patients the rt-PA injections were repeated once, in six patients three injections of rt-PA were required. One patient received four injections of rt-PA. In patients with intraventricular haematoma due to ruptured aneurysm, haematoma lysis was initiated after clipping the aneurysm. In patients with IVH due to arteriovenous malformation, fibrinolytic treatment preceded excision of the angioma. In all patients the rt-PA treatment was started 12 to 48 hours after onset of the symptoms. Coagulation profiles were obtained before and after rt-PA treatment to rule out any systemic coagulopathy.

Table 2 Grading system for assessment of severity of intraventricular haemorrhage 6

Lateral ventricles (each ventricle is scored separately) Trace of intraventricular blood or mild bleeding: score Less than half of the ventricle filled with blood: score 2 More than half of the ventricle filled with blood: score 3 Ventricle filled with blood and expanded: score 4

Third and fourth ventricles (each ventricle is scored separately) Blood present, ventricle size normal: score 1

Ventricle filled with blood and expanded: score 2

Maximum score $=12$.

\section{Results}

Complete removal or substantial reduction of haematoma size in the lateral ventricles was achieved in 19 of 20 patients within one to three days (mean 1.8 days). In the cases of incomplete clearance, the remaining blood did not exert local mass effect. In 19 of 20 patients the blood clots in the third and fourth ventricles were completely lysed in one to two days (mean 1.2 days) after initiation of the intraventricular rt-PA treatment (figure). In all cases the size of the accompanying intracerebral haematoma remained unchanged. Decrease of ventricular enlargement was seen in all but one patient with initial ventricular dilatation. The ventriculocranial ratio improved from a mean of 0.23 (pretreatment) to 0.17 (post-treatment) (table 1). In one patient with IVH extending into all ventricular chambers and rapid neurological deterioration, bilateral ventriculostomy was performed. Without confirmation of uneventful ventriculostomy by CT, $2.5 \mathrm{mg}$ of rt-PA were injected into both lateral ventricles. Computed tomography obtained 16 hours after rt-PA treatment showed an increase in haematoma volume and ventricular ratio. In this patient as well as in the other patients systemic coagulopathy was ruled out. There were no other complications related to intraventricular rt-PA treatment.

In all patients the ventriculostomy needle remained patent during the period of external CSF drainage. The ventricular drain was removed after a mean duration of 23.3 days. Eleven patients developed progressive hydrocephalus after ventriculostomy removal and required ventriculoperitoneal shunt placement.

Four patients recovered completely (GOS 1) and five patients showed only minor neurological deficits (GOS 2). Six patients exhibited incomplete recovery (GOS 3). Four patients became vegetative (GOS 4), and 
Computed tomography in a 47 year old man (patient 6) who presented with severe disturbance of consciousness and

decorticate posturing.

Admission CT showed a severe intraventricular haemorrhage and subarachnoid haemorrhage caused by an

angiographically verified aneurysm of the anterior communicating artery.

Upper: CT obtained immediately after aneurysm clipping and before first intraventricular injection of $5 \mathrm{mg}$ of $\mathrm{rt}-\mathrm{PA}$.

Upper, centre: $C T$

obtained 24 hours after aneurysm clipping and first intraventricular injection of $5 \mathrm{mg}$ of $\mathrm{rt}-\mathrm{PA}$. Lower, centre: $C T$ obtained 24 hours after second intraventricular injection of $5 \mathrm{mg}$ of $\mathrm{rt}-\mathrm{PA}$. Lower: $C T$ obtained 48 hours after the third and 24 hours after the fourth injection of $5 \mathrm{mg}$ of $r t-P A$ showing only traces of blood in both lateral ventricles and appreciable reduction of ventricular size.

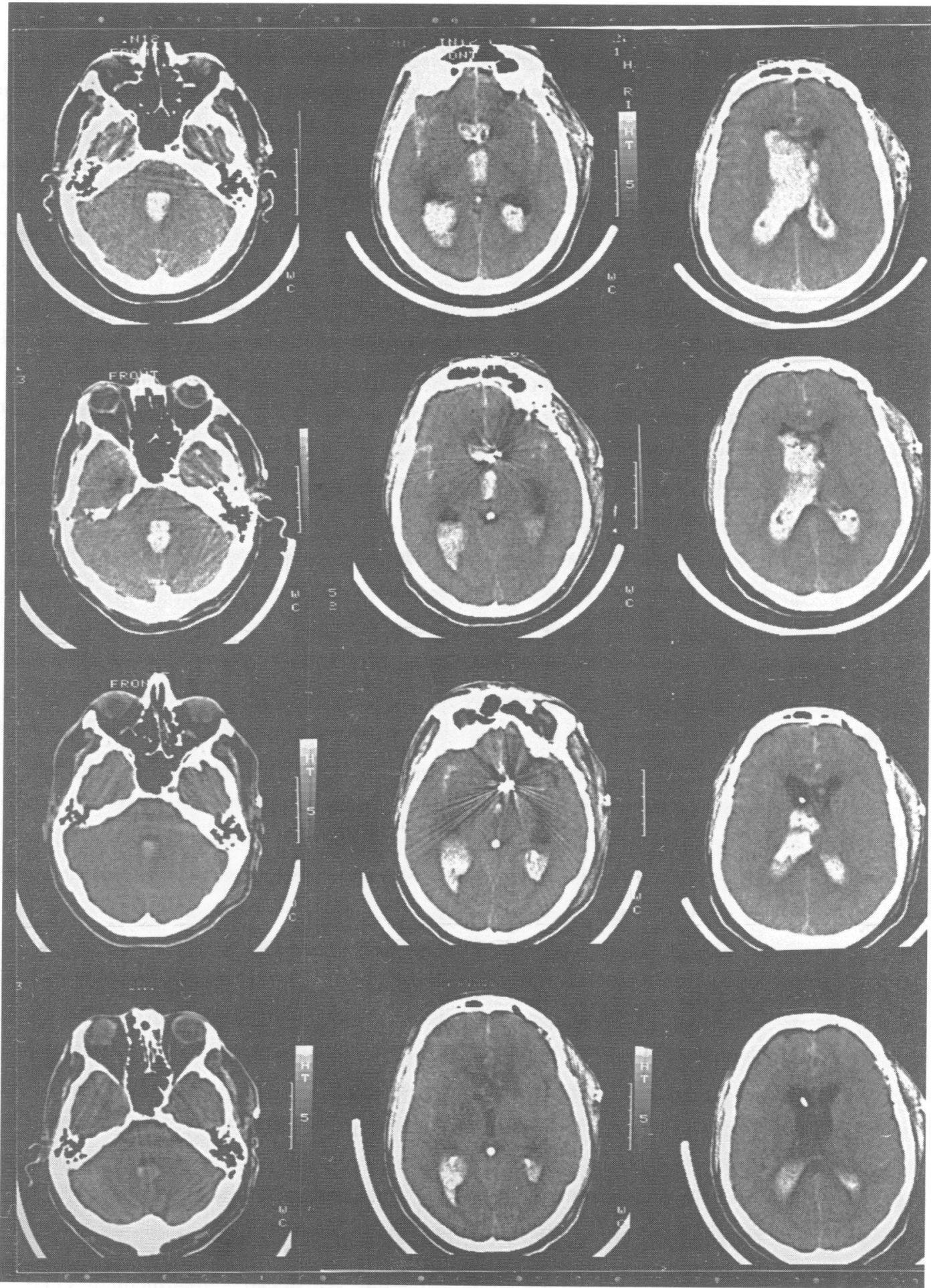

one patient did not survive the IVH (GOS 5; table 1).

\section{Discussion}

CAUSES AND NATURAL HISTORY OF IVH

Forty six to $62 \%$ of intraventricular haematomas result from penetration of a hypertensive or arteriosclerotic intracerebral haemorrhage into the ventricles. ${ }^{517}$ Nineteen to $29 \%$ of IVHs are caused by rupture of cerebral aneurysms, predominantly arising from the anterior communicating artery and the anterior cerebral artery. ${ }^{56}$ Less frequent causes of IVH are periventricular arterio- venous malformations, head trauma, and tumours.

Intraventricular haemorrhage carries a poor prognosis. The mortality for IVH is related to the amount of intraventricular blood and increases from $32.2 \%$ in cases with mild haemorrhage to $91 \%$ in cases with complete haematocephalus. ${ }^{469}$

\section{PATHOPHYSIOLOGY OF IVH}

A consequence of intraventricular bleeding is impaired circulation of CSF. Acute occlusive hydrocephalus and the direct mass effect of the intraventricular haematoma result in dilatation of the ventricular system. The 
ventricular enlargement raises the intracranial pressure and reduces the periventricular cerebral blood flow. Mohr et al retrospectively studied 91 cases with aneurysmal IVH. ${ }^{3}$ The degree of ventricular enlargement correlated with the prognosis of aneurysmal IVH, indicating that ventricular enlargement is the major pathophysiological mechanism in IVH.

\section{MANAGEMENT BY VENTRICULOSTOMY}

Intraventricular haematomas are managed by external ventricular drainage with or without valve regulation. ${ }^{9}{ }^{18} 19$ Rapid reduction of ventricular dilatation with consecutive improvement of intracranial pressure and cerebral blood flow is rarely achieved by ventriculostomy because the ventricular drainage usually does not effect the volume of the intraventricular haematoma and only unreliably drains the hydrocephalus because of frequent obstruction with clotted blood. ${ }^{911}$ Therefore external ventricular drainage failed to contribute to better outcome in IVH. ${ }^{9}$

\section{FIBRINOLYTIC TREATMENT OF IVH}

After successful lysis of experimental subtotal intraventricular haematoma in animal models with urokinase, Shen et al reported clot disappearance or its reduction to a minimum within five to six days in four patients with severe IVH after intraventricular injection of urokinase. $^{2013}$ The results were confirmed by Todo et al. They treated six patients with moderate to severe IVH by intraventricular infusion of urokinase; this resulted in clearance of the ventricles seven to eight days after haemorrhage. Eighty three per cent of the patients showed good to excellent outcome. ${ }^{7}$ After studies in primates and clinical trials had shown that intracisternal application of the fibrinolytic agent rt-PA is effective in lysing subarachnoid blood and preventing cerebral vasospasm, intraventricular infusion of rt-PA for treatment of moderate to severe IVH due to ruptured aneurysms and hypertensive intracerebral haemorrhage was performed recently in a small number of patients. ${ }^{12} 21-27$

Our results show that disappearance of blood clots or clot lysis to a minimum is achieved within 24 to 72 hours after intraventricular injection of 2 to $5 \mathrm{mg}$ of rt-PA per day. The normalisation of the ventricular enlargement (pretreatment mean ventriculocranial ratio 0.23 ; post-treatment mean ventriculocranial ratio $0 \cdot 17$ ) indicates that the successful clot lysis results in reduction of the direct mass effect and improvement in the circulation of CSF. The thrombolytic efficacy of rt-PA is higher than that of urokinase. ${ }^{28}$ Intraventricular injection of 10000 to 96000 IU urokinase resulted in haematoma lysis within five to eight days, whereas intraventricular fibrinolytic treatment with 2 to $5 \mathrm{mg}$ rt-PA achieved blood clot disappearance within one to three days. ${ }^{713} \mathrm{We}$ prefer rt-PA to urokinase for treatment of IVH because the accelerated decrease of ventricular dilatation could help to reduce secondary brain damage.

\section{COMPLICATIONS}

In one patient with IVH and hypertensive brain haemorrhage the volume of the intraventricular haematoma increased after initiation of the rt-PA treatment. Because of a deviation from the treatment protocol, uneventful bilateral ventriculostomy was not confirmed by CT in this patient before intraventricular rt-PA injection. It remained unclear whether complication of ventriculostomy or an rt-PA induced rebleed caused haematoma enlargement. In our series as well as in the clinical studies of intracisternal and intraventricular application of rt-PA, systemic fibrinolysis or coagulopathy were not found. 122426

Mayfrank et al reported one fatal meningitis related to treatment with intraventricular rtPA. ${ }^{12}$

In our series and in the series of Mayfrank et al the volume of accompanying intracerebral haematoma remained unchanged during rt-PA treatment. ${ }^{12}$ In the clinical studies of intracisternal application of rt-PA for the prevention of cerebral vasospasm after aneurysmal subarachnoid haemorrhage, epidural haematoma and increase in subarachnoid blood were noted but no intracerebral bleeding complication was found. ${ }^{26} 29$ These findings suggest that the fibrinolytic effect of rt-PA given intraventricularly is predominantly limited to the CSF pathways. Therefore, we believe that definitive haemostasis before the use of intraventricular rt-PA is not necessary in patients with an intracerebral source of bleeding.

\section{PROGNOSIS}

Our results suggest that efficacious haematoma lysis improves the poor prognosis of moderate to severe IVH. The mortality of $5 \%$ in our series is much lower than the mortalities of $60 \%$ to $91 \%$ in patients with moderate to severe IVH not subjected to intraventricular fibrinolytic treatment. Hypertensive or arteriovenous malformation associated intracerebral haemorrhage and aneurysm rupture also cause direct brain damage, which contributes to morbidity and mortality of IVH and is not influenced by intraventricular rt-PA treatment. Before accepting intraventricular rt-PA as standard treatment of IVH a placebo controlled randomised clinical study would be necessary to show that rt-PA is truly effective and success is not the consequence of selection criteria. From the ethical point of view a placebo controlled randomised trial is questionable. Fibrinolytic treatment would have to be withheld from severely ill patients to recruit the placebo group even though data highly suggestive of a beneficial effect of rt-PA already exist. To overcome this problem patients from whom informed consent was not obtained could be assigned to the placebo group. Until completion of the randomised trial the lower mortality in our series justifies the continuation of the relatively safe and easy intraventricular fibrinolytic rt-PA treatment for moderate to severe IVH. 
This work was presented in part at the 61 st Annual Meeting of the American Association of Neurological Surgeons in Boston 24-29 April, 1993.

1 Adams HP, Torner JC, Kassell NF. Intraventricular hemorrhage among patients with recently ruptured aneurysms: a report of the cooperative aneurysm study [abstract]. Stroke 1992;23:140.

2 Helweg-Larsen S, Sommer W, Strange P, et al. Prognosis for patients treated conservatively for spontaneous intracerebral hematomas. Stroke 1984;15:1045-8.

3 Mohr G, Ferguson G, Khan M, et al. Intraventricular hemorrhage from ruptured aneurysm. Retrospective hemorrhage from ruptured aneurysm. Retrosp

4 Ruscalleda J, Peiró A: Prognostic factors in intraparenchymatous hematoma with ventricular hemorrhage. Neuroradiology 1986;28:34-7.

5 Donauer E, Reif J, Al-Khalaf B, et al. Intraventricular haemorrhage caused by aneurysms and angiomas. Acta Neurochir 1993;122:23-31

6 Graeb DA, Robertson WD, Lapointe JS, et al. Computed tomographic diagnosis of intraventricular hemorrhage. Radiology 1982;143:91-6.

7 Todo T, Usui $M$, Takakura $K$. Treatment of severe intraventricular hemorrhage by intraventricular infusion of urokinase. $\mathcal{F}$ Neurosurg 1991;74:81-6.

$8 \mathrm{Pia} \mathrm{HW}$. The surgical treatment of intracerebral and intraventricular haematomas. Acta Neurochir 1972;27: 149-64.

9 Little JR, Blomquist GA Jr, Ethier R. Intraventricular hemorrhage in adults. Surg Neurol 1977;8:143-9.

10 Akimort $\mathrm{Maki} Y$. Serial C orrhage. No Shinkei Geka 1979;7:455-64.

11 Findlay JM, Weir BKA, Stollery DE. Lysis of intraventricular hematoma with tissue plasminogen activator. Case report. $\mathcal{F}$ Neurosurg 1991;74:803-7.

12 Mayfrank L, Lippitz B, Groth M, et al. Effect of recombinant tissue plasminogen activator on clot lysis and ventricular dilatation in the treatment of severe intraventricular haemorrhage. Acta Neurochir 1993;122 32-8.

13 Shen PH, Matsuoka Y, Kawajiri K, et al. Treatment of intraventricular hemorrhage using urokinase. Neurol Med Chir (Tokyo) 1990;30:329-33.

14 Vassilouthis J, Richardson AE. Ventricular dilatation and communicating hydrocephalus following spontaneous

15 Teasdale G, Jennett B. Assessment of coma and impaired consciousness. A practical scale. Lancet 1974;ii:81-4.

16 Jennett B, Bond M. Assessment of outcome after severe brain damage. A practical scale. Lancet 1975;i:480-4.
17 Wiggins WS, Moody DM, Toole JF, et al. Clinical and iggins WS, Moody DM, Toole JF, et al. Clinical and computerized tomographic study of hypertensive

18 Chan KH, Mann KS. Intraventricular haematoma: management of comatose patients with valve regulated external ventricular drainage. $B r \mathcal{F}$ Neurosurg 1988;2:465-9.

19 Loew FD, Jaksche H. IVH surgical treatment: possibilitie of operative treatment and its limitations, in Pia $\mathrm{HW}$, Langmaid C, Zierski J, et al, eds. Spontaneous intracerebral hematomas. Berlin: Springer, 1980:281-3.

20 Pang D, Scalabassi RJ, Horton JA. Lysis of intraventricular blood clot with urokinase in a canine model: part 3 . Effects of urokinase on clot lysis and posthemorrhagic hydrocephalus. Neurosurgery 1986;19:553-72.

21 Findlay JM, Weir BKA, Kassell NF, et al. Intracisternal recombinant tissue plasminogen activator after aneurysrecombinant tissue plasminogen activator after aneurysmal subar $181-8$.

22 Hariton GB, Findlay JM, Weir BKA, et al. Comparison of intrathecal administration of urokinase and tissue plasminogen activator on subarachnoid clot and chronic vasospasm in a primate model. Neurosurgery 1993;33: 691-7.

23 Mizoi K, Yoshimoto T, Takahashi A, et al. Prospective study on the prevention of cerebral vasospasm by intrathecal fibrinolytic therapy with tissue-type plasminogen activator. $\mathcal{F}$ Neurosurg 1993;78:430-7.

24 Öhman J, Servo A, Heiskanen O. Effect of intrathecal fibrinolytic therapy on clot lysis and vasospasm in patients with aneurysmal subarachnoid hemorrhage. $\mathcal{F}$ Neurosurg 1991;75:197-201.

25 Seifert V, Eisert WG, Stolke D, et al. Efficacy of single intracisternal bolus injection of recombinant tissue plasmintracisternal bolus injection of recombinant tissue plasminogen activator to prevent delayed cerebral vasospasm after experimental subar
Neurosurgery 1989;25:590-8.

26 Zabramski JM, Spetzler RF, Lee KS, et al. Phase I trial of issue plasminogen activator for the prevention of vasospasm in patients with aneurysmal subarachnoid hemorrhage. f Neurosurg 1991;75:189-96.

27 Findlay JM, Grace MGA, Weir BKA. Treatment of intraventricular hemorrhage with tissue plasminogen activator. Neurosurgery 1993;32:941-7.

28 Zimmermann R, Gürsoy A, Horn A, et al. Fibrinolytic therapy of deep vein thrombosis with continuous intravenous infusion of a recombinant tissue plasminogen activator. Seminars in thrombosis and hemostasis 1991; 17:48-54.

29 Sasaki T, Ohta T, Kikuchi H, et al. A phase II clinical trial of recombinant human tissue-type plasminogen activator against cerebral vasospasm after aneurysmal subarachnoid hemorrhage. Neurosurgery 1994;35:597-605. 